\title{
O sistema de cavalgamentos do tipo duplex Neoproterozoico da Serra do Espinhaço, Minas Gerais
}

\author{
Rogério Rodrigues da Silva ${ }^{1}$
}

\begin{abstract}
Resumo Utilizando critérios de aloestratigrafia durante o mapeamento geológico de uma área de aproximadamente $1.600 \mathrm{~km}^{2}$ foi interpretado que o arcabouço estrutural da Serra do Espinhaço em Minas Gerais consiste de um sistema de cavalgamentos do tipo duplex de importância regional. As duas zonas de cisalhamentos principais do duplex (zonas de cisalhamento basal e de teto) são conectadas entre si através de um sistema de cavalgamentos subsidiários menores, formando um sistema de cavalos tectônicos. Acima da zona de cisalhamento de teto, a deformação é representada por um leque imbricado de lentes tectônicas, que convergem para baixo na zona de cisalhamento principal de teto. Deformação por cisalhamento simples, heterogênea, rúptil/dúctil, de caráter progressivo, com transporte tectônico para oeste, desenvolveu o sistema de cavalgamentos do tipo duplex durante uma fase de deformação inicial (D1). Uma fase de deformação posterior (D2) causou encurtamento crustal através de dobramentos assimétricos generalizados e pela reativação das falhas da fase D1. Metamorfismo progressivo sintectônico produziu a cristalização de associações de minerais características das condições da fácies xisto verde baixo.
\end{abstract}

Palavras-chave: mapeamento geológico, análise estrutural de terrenos Proterozoicos, sistema de cavalgamentos do tipo duplex.

\begin{abstract}
The Neoproterozoic duplex thrust system of the Serra do Espinhaço, Minas Gerais. Based on allostratigraphic criteria used during geological mapping of an area of approximately $1,600 \mathrm{~km}^{2}$, it was interpreted that the structural framework of the Serra do Espinhaço in Minas Gerais consists of a duplex thrust system of regional importance. The two main shear zones of the duplex (roof- and sole-shear zones) are connected one to another by a system of minor subsidiary thrusts, forming a system of tectonic horses. Above the roof-shear zone, deformation is represented by an array of embricated tectonic fans, where thrusts converge below into the main roof-shear zone. Heterogeneous, progressive in character, brittle/ductile, simple-shear deformation, with tectonic transport directed towards the west, developed the duplex thrust system, during an initial phase of deformation (D1). A second deformational phase (D2) caused crustal shortening by generalized asymmetric folding and reactivation of D1 thrust-planes and shear-zones. Syntectonic progressive metamorphism produced the crystallization of a mineral association typical of lower greenschist facies conditions.
\end{abstract}

Keywords: geological mapping, structural analysis of Proterozoic terrains, duplex thrust system.

INTRODUÇÃo A questão central explicitada neste artigo é a utilização de métodos e conceitos de aloestratigrafia para subdividir, mapear e analisar o registro geológico das faixas móveis Proterozoicas, periféricas ao Cráton do São Francisco. Trabalhos de mapeamento geológico com esta ênfase foram desenvolvidos nas sucessões metassedimentares que constituem a Serra do Espinhaço em Minas Gerais (Silva 1993, 1995) e na Bahia (Danderfer \& Dardenne 2002, Dominguez 1993) e na região de São João Del Rei (Ribeiro 1997, Ribeiro et al. 1997). Através do mapeamento geológico de unidades aloestratigráficas foi possível estabelecer com maior clareza e detalhe a história estratigráfica destas sucessões. Nas faixas móveis periféricas ao Cráton do São Francisco, o mapeamento geológico tem sido historicamente conduzido com base em critérios litoestratigráficos, abordagem disponível nas décadas de 50 e 60, antes do advento da aloestratigrafia. A utilização continuada de critérios litoestratigráficos pela comunidade geológica (empresas, universidades e instituições afins) acarretou a proliferação exagerada de nomes de unidades estratigráficas, que confundem e atrapalham as interpretações. Outra consequência é a produção de mapas geológicos de difícil leitura, o que impede a identificação do arcabouço tectônico, superimposto nas sucessões sedimentares.

Neste trabalho, a sequência deposicional foi utilizada como unidade básica da análise estratigráfica, assim como fez Silva em 1995. A sequência deposicional é definida como "uma sucessão de estratos sedimentares, geneticamente relacionados e relativamente concordantes, limitados na base e no topo por discordâncias e suas conformidades correlativas" (Posamentier et al. 1988). O uso de conceitos básicos da Estratigrafia 
de Sequências incluiu também a identificação dos sistemas deposicionais e de contatos sedimentares dos tipos onlap e downlap e suas implicações paleogeográficas e cronoestratigráficas. As sequências deposicionais foram então agrupadas em unidades geneticamente relacionadas, individualizadas como unidades no mapa geológico. Cada uma destas unidades representa uma fase distinta da evolução tectônica/estratigráfica das bacias sedimentares do Espinhaço e São Francisco, mais antigas que a orogênese Neoproterozoica (Silva 1996, 1999). Os depósitos eólicos que ocorrem na Bacia do Espinhaço foram mapeados em separado dos depósitos da fase rift 1. Entende-se, entretanto, que estes depósitos pertençam geneticamente àquela fase.

A coluna litoestratigráfica elaborada por Pflug (1968) serve ainda hoje como referência para a Serra do Espinhaço em Minas Gerais. O autor identificou sete formações, subdividindo a coluna estratigráfica da Série Minas, equivalente ao Supergrupo Espinhaço de Pflug \& Renger (1973). Schöll (1980) e Schöll \& Fogaça (1981) mapearam em detalhe a região de Diamantina e subdividiram a estratigrafia levantada anteriormente por Pflug (1968). Por outro lado, trabalhos de levantamento de colunas estratigráficas a partir do mapeamento sistemático de discordâncias na região são recentes e ainda limitados a poucos autores. Mapeamento geológico detalhado de sequências deposicionais foi realizado na região por Silva $(1993,1994,1995,1996,1999)$. Os resultados obtidos pelo autor são usados como base neste trabalho. $\mathrm{O}$ conceito de tectonoestratigrafia e a definição de tectonosequências, apresentados por Martins-Neto $(1995,1998)$, confirmou em parte o esquema aloestratigráfico desenhado anteriormente para a Serra do Espinhaço em Minas Gerais.

O objetivo deste artigo é descrever o arcabouço estrutural da Serra do Espinhaço na região estudada, adquirido em decorrência da orogênese Neoproterozoica. O mapa geológico apresentado compreende uma área de aproximadamente $1.600 \mathrm{~km}^{2}$, mapeada em sua totalidade na escala de 1:25.000 e, localmente, em escalas mais detalhadas. Sistema de cavalgamentos do tipo duplex Neoproterozoicos tem sido descrito na Serra do Espinhaço em Minas Gerais. Marshak \& Alkmim (1989) interpretaram o cavalgamento frontal na borda oeste da cordilheira como uma falha do tipo "detachment", com um sistema de cavalgamentos duplex desenvolvido acima deste. Kalt (1991), Rolim (1992) e Dossin et al. (1992) também especularam a respeito da existência de sistema de cavalgamentos do tipo duplex nesta região, apesar de não terem localizado, nem sequer descrito as características básicas deste sistema. Silva \& Toledo (1994), Silva $(1995,2008)$ apresentaram perfil geológico da região, corroborando com a interpretação da existência de sistema de cavalgamentos do tipo duplex, de importância regional. Cruz et al. (2005) apresentou mapa geológico/estrutural detalhado da área de Gouveia. Estes autores não interpretaram a existência de sistema de cavalgamentos do tipo duplex.
CONTEXTO GEOLÓGICO A Serra do Espinhaço em Minas Gerais é constituída por um complexo de rochas ígneas associadas com rochas metamórficas de alto grau de Idade Arqueana e duas sucessões de rochas de origem sedimentar e subordinadamente vulcânica, denominadas de Supergrupo Espinhaço e Supergrupo São Francisco, depositadas respectivamente nas Bacias do Espinhaço e São Francisco de idade Proterozoica. Todo esse conjunto foi deformado e metamorfisado durante o Neoproterozoico, constituindo a Faixa Móvel Araçuaí, localizada à sudeste do Cráton do São Francisco (Fig. 1).

As rochas metassedimentares pertencentes à Bacia Espinhaço estão separadas do embasamento Arqueano por uma discordância, e no topo são profundamente erodidos através de uma discordância de importância regional. Esta discordância marca o início da sedimentação na Bacia São Francisco, que, em relação à Bacia Espinhaço, possui depocentro deslocado para leste.

O complexo do embasamento do Arqueano consiste de rochas ígneas, predominantemente granitos e granodioritos, associados com migmatitos. A determinação de idade, utilizando o método $\mathrm{U} / \mathrm{Pb}$ em zircões, indicou que a cristalização primária de granitos, intrusivos no complexo Arqueano, ocorreu há 2,8 Ga (Machado et al. 1989). Durante a orogênese Paleoproterozoica, entre 2,2 e 2,0 Ga, o complexo ígneo/migmatítico de rochas do embasamento foi retrabalhado (Danderfer $e t$ al. 2009). Esta idade indica a idade máxima para o início da sedimentação na Bacia Espinhaço.

A Fase Pré-Rift 1 é representada pela Sequência Deposicional Rio Paraúna, constituída por uma sucessão epiclástica, com gradação inversa (granocrescência-ascendente), que pode possuir até mais $600 \mathrm{~m}$ de espessura. Na base, metapelitos puros, maciços, recobrem diretamente o embasamento Arqueano. Em direção ao topo, o aumento da granulometria acarreta o aumento da quantidade de grãos detríticos com a fração areia. Foram assim depositados os protólitos dos sericita-quartzo-xistos, com cianita e que gradativamente transicionam para o topo para metarenitos, alguns com marcas de onda reconhecíveis. O contato de topo dos depósitos pré-rift é marcado por discordância, que marca o início da fase rift 1 (Fig. 2).

Durante a Fase Rift 1 da Bacia do Espinhaço foram acumuladas as Sequências Deposicionais, da base para o topo: Olaria, Natureza, São João da Chapada e Sopa-Brumadinho/Galho do Miguel. As Sequências Deposicionais Olaria, Natureza e São João da Chapada apresentam discordâncias basais que são recobertas por sedimentos continentais de natureza aluvial, predominantemente metaconglomerados. No topo destas sequências ocorrem metarenitos e metapelitos de origem marinha rasa. O desenvolvimento das discordâncias sedimentares e a deposição dos metaruditos continentais foram controlados por tectonismo distensivo, responsável pelo rebaixamento relativo do nível de base da bacia (nível do mar) (Fig. 3). A deposição dos sedimentos de origem marinha foi induzida por movimentos 
eustáticos positivos, acarretando a subida relativa do nível do mar e a consequente produção de espaço para acomodação dos sedimentos.

Os metaconglomerados diamantíferos famosos da Sequência Deposicional Sopa-Brumadinho/Galho do Miguel foram depositados em deltas alimentados por detritos oriundos da erosão nas cabeceiras fluviais. Nova transgressão se sucede e no topo, depósitos de origem eólica recobrem os depósitos da fase rift 1 da Bacia Espinhaço. Indicam longo período de estabilidade

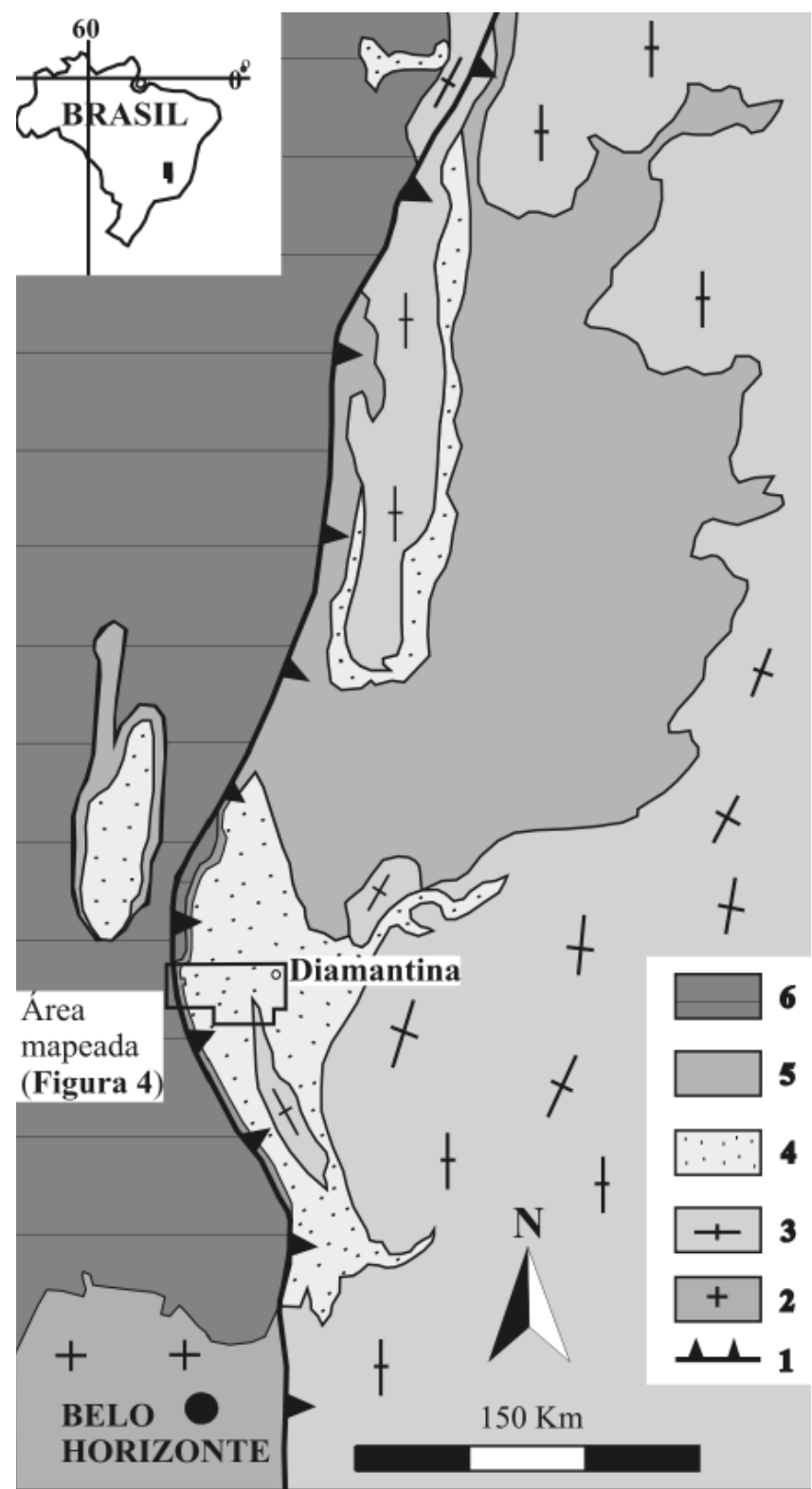

Figura 1 - Mapa geológico da Serra do Espinhaço em Minas Gerais (Schobbenhaus 1993, Pflug \& Renger 1973). Legenda: 1 = limites cratônicos; $2=$ Embasamento Arqueano; 3 = Embasamento Arqueano retrabalhado durante a orogênese Neoproterozoica; $4=$ Supergrupo Espinhaço; 5 = Supergrupo São Francisco (Grupo Macaúbas e 6 = Supergrupo São Francisco (Grupo Bambui). tectônica, após a etapa anterior, de natureza tectônica e eustática (Silva 1995).

A Fase Rift 1 da Bacia Espinhaço é marcada por magmatismo bimodal, tanto efusivo quanto plutônico. Este magmatismo é representado por rochas metaefusivas de caráter básico, filitos hematíticos da região de Diamantina e caráter ácido, metarriolitos na borda leste da cordilheira. Estas rochas forneceram a idade de $1,7 \mathrm{Ga}$, através das datações de zircões pelo método $\mathrm{U} / \mathrm{Pb}$ (Brito-Neves et al. 1979, Machado et al. 1989). As rochas vulcânicas possuem filiação genética com os magmatitos de caráter ácido, denominados de "granitos borrachudos", encontrados na forma de corpos isolados, intrusivos no complexo ígneo do embasamento, na região da borda leste da cordilheira. A idade de 1,7 Ga marca claramente uma etapa de atividade tectônica e magmática intensa ocorrida durante a fase rift da Bacia do Espinhaço, mais precisamente durante a deposição da Sequência Deposicional São João da Chapada.

A Fase Flexural é representada pela Sequência Deposicional Conselheiro Mata. Foi depositada diretamente acima dos depósitos eólicos, que caracterizam o fim da fase rift 1. É constituída por três sucessões regressivas, com gradação inversa (granocrescênciaascendente), separadas entre si por superfícies de inundação marinha. Apresentam na base, como regra, metapelitos distais recobertos por arenitos de origem plataformal e marinho-raso. A base dos ciclos é abrupta, enquanto a variação faciológica dentro dos ciclos é transicional. As estruturas sedimentares observadas em cada ciclo regressivo fornecem indicações da diminuição progressiva da profundidade da lâmina de água, na medida em que a sedimentação progride. Bancos métricos de metadolomitos com estromatólitos foram depositados em plataformas muito rasas, e caracterizam o topo dos depósitos da Bacia Espinhaço (Silva 1999).

Uma discordância sedimentar de importância regional separa os depósitos das Bacias Espinhaço e São Francisco. De oeste para leste, esta discordância marca a erosão profunda dos depósitos da Bacia do Espinhaço, até alcançar o Embasamento Arqueano, deslocando o depocentro da Bacia São Francisco para leste (Silva 1996). Concomitante ao tectonismo sin-sedimentar ocorreu uma glaciação continental, responsável pelo rebaixamento eustático rápido do nível do mar. Sinais de exposição subaérea são observados nos metadolomitos, depositados no topo da Bacia Espinhaço, com carstificação e posterior preenchimento das cavidades por detritos de origem glacial (Silva 1999). Depósitos glaciais, metadiamictitos e depósitos das planícies aluviais de áreas periféricas às geleiras continentais, metaconglomerados, recobrem a discordância basal da Bacia São Francisco e alimentaram nas porções distais, para leste, correntes de turbidez (Fase Rift 2). Após o período de glaciação, decorrente do derretimento das calotas polares, movimentos de eustasia positivo acarretaram a transgressão do mar acima do cráton. Esta transgressão é responsável pela deposição dos metassiltitos e metacalcáreos, acima dos depósitos mais antigos (Fase Transgressiva) (Silva 1999). 


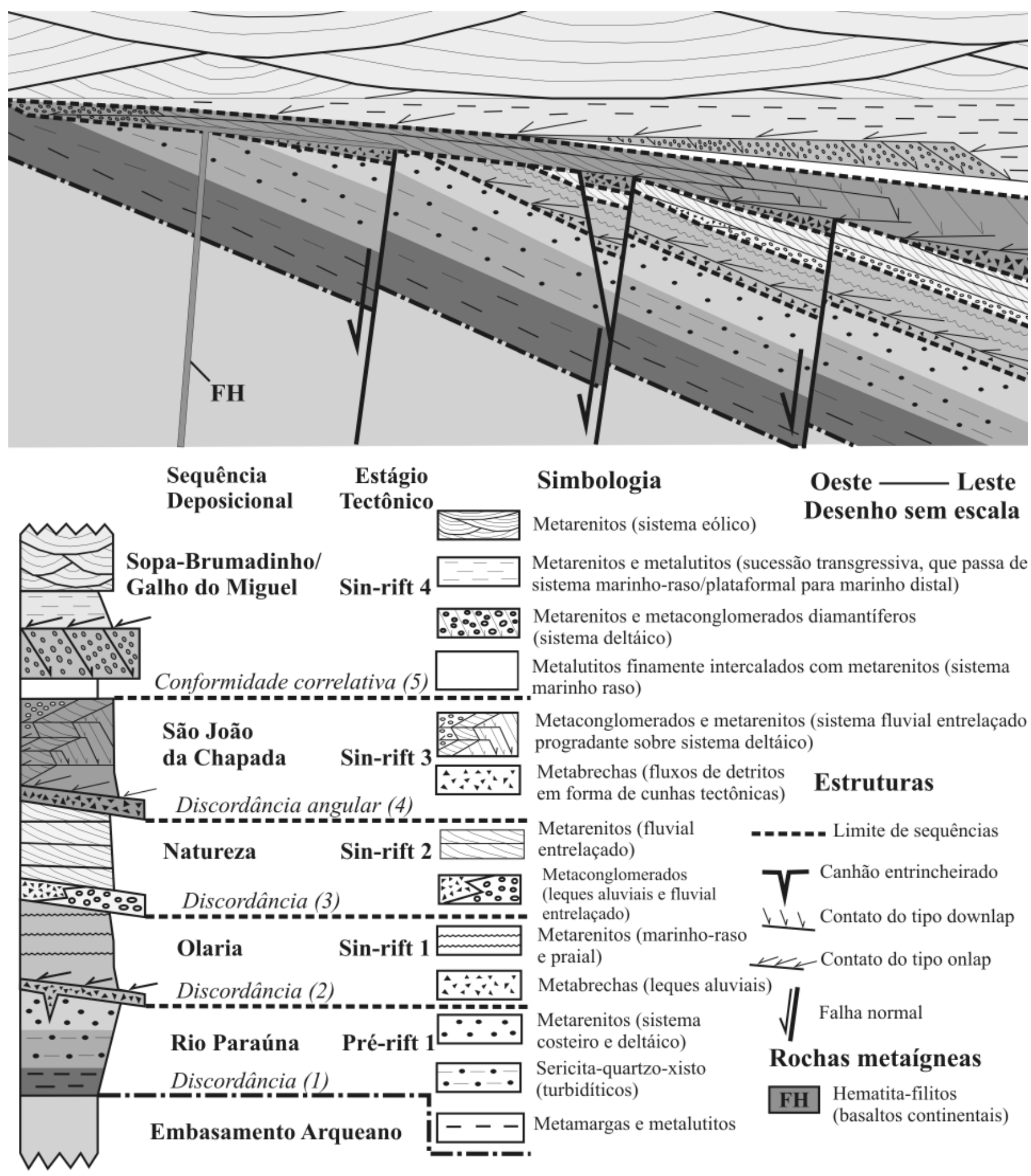

Figura 2 - Perfil estratigráfico esquemático da área de Diamantina, apresentando as relações entre as sequências deposicionais das fases pré-rift e rift 1 da evolução da Bacia do Espinhaço, na área de Diamantina (Silva 1995, modificado).

A sedimentação na Bacia São Francisco é mais jovem que $0,9 \mathrm{Ga}$, como demonstrado pelas datações de zircões pelo método $\mathrm{U} / \mathrm{Pb}$, obtidos de diques intrusivos básicos, que cortam os depósitos da Bacia do Espinhaço, mas não cortam através dos depósitos da
Bacia São Francisco (Machado et al. 1989). Martins et al. (2008), com base em datação geocronológica de zircões detríticos, amostrados nas rochas que recobrem a discordância da base da Bacia São Francisco, interpreta que a sedimentação teve início a partir de 1,16 Ga. 

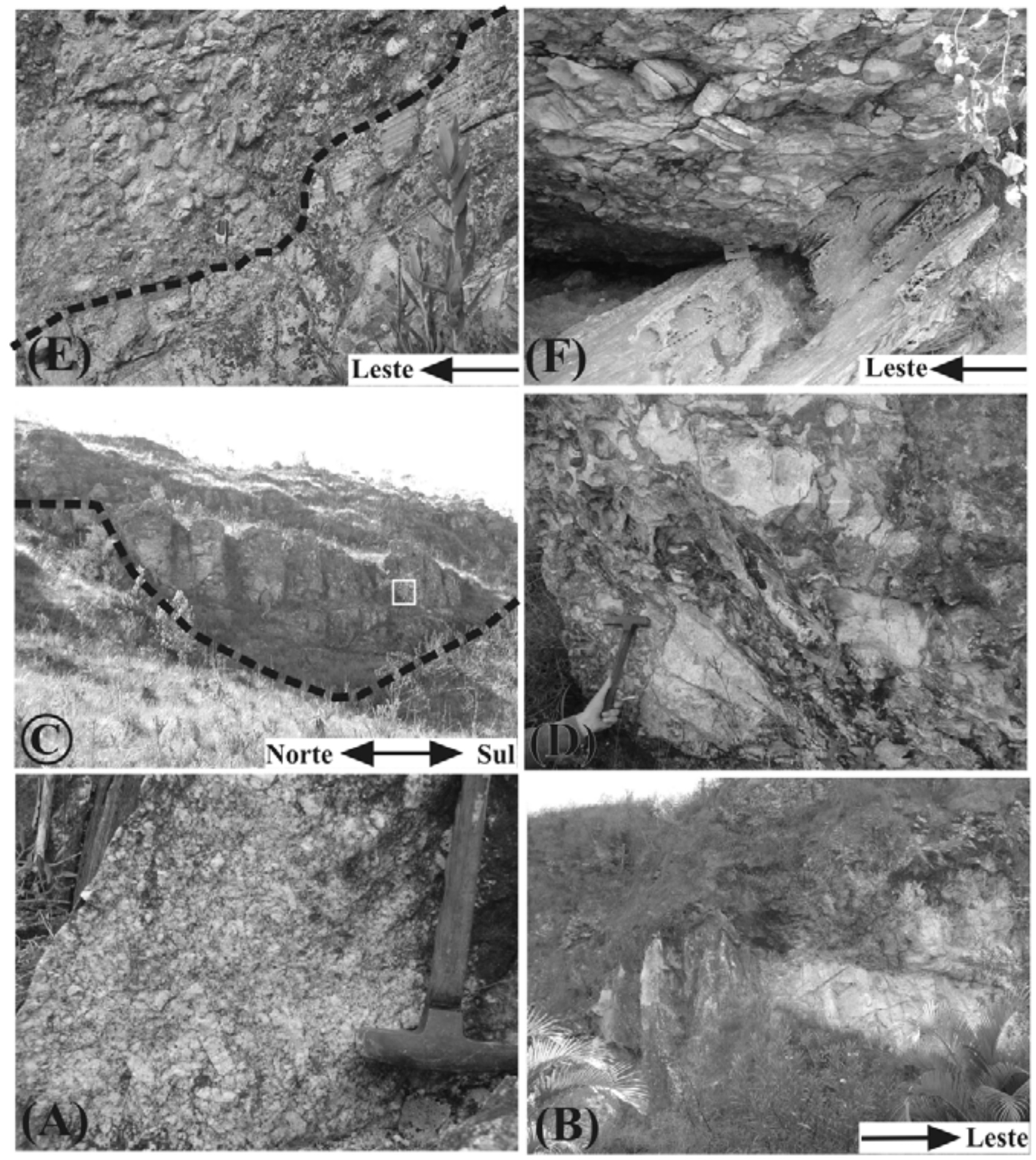

Figura 3 - (A) Granito porfiritico de Gouveia. (B) Discordância basal da Bacia do Espinhaço, apresentando o contato do granito de Gouveia com os metassedimentos da fase pré-rift 1. (C) Discordância basal da Sequência Deposicional Olaria, representada pelo canhão de vale aluvial entrincheirado em metarenitos. (D) Metabrecha que preenche o vale aluvial entrincheirado. Para localização ver caixa na figura anterior. (E) Discordância basal da Sequência Deposicional Natureza, recoberta por metaconglomerados de origem fluvial entrelaçado. (F) Discordância angular basal da Sequência Deposicional São João da Chapada, recoberta por metaconglomerados originados por fluxos de detritos continentais.

A tafrogênese (Fase Rift 2) teve seu ponto culminante há $0,8 \mathrm{Ga}$, com a fragmentação continental e o desenvolvimento de crosta oceânica (Pedrosa-Soares et al.
1992). Os registros estratigráficos das duas bacias estão relacionados à fragmentação continental completa do Embasamento Arqueano, culminando com a formação 
de crosta oceânica (Silva 1996, 1999). Martins-Neto (1995, 1998) e Danderfer \& Dardenne (2002) interpretaram que a Bacia do Espinhaço não evolui para a Bacia do São Francisco, expressando ambas as bacias uma evolução poli-histórica e descontínua durante o Proterozoico. A sedimentação na Bacia São Francisco terminou antes da orogênese Neoproterozoica, aproximadamente há $0,6 \mathrm{Ga}$, quando ocorreu a inversão tectônica das bacias sedimentares Proterozoicas.

O ARCABOUÇO ESTRUTURAL A figura 4 apresenta o mapa geológico da região a oeste de Diamantina. O sistema de cavalgamentos do tipo duplex é composto por duas zonas de cisalhamento principais (basal e de teto), sub-horizontais e que se conectam entre si através de um sistema de cavalgamentos subsidiários menores.

A zona de cisalhamento de teto do duplex aflora nas porções centrais da área mapeada, com exposição de norte até sul no mapa geológico. A zona de cisalhamento possui até $10 \mathrm{~m}$ de espessura, com desenvolvimento de foliação tectônica anastomosada marcante, associada com quartzo de veios. O mapa geológico mostra o cisalhamento de teto do duplex passando por cima do sistema de cavalgamentos subsidiários, aparentemente truncando estes cavalgamentos. Metassedimentos de origem eólica são encontrados acima da zona de cisalhamento de teto e encontram-se orientados de forma concordante com este. Uma klippe tectônica é observada na área à SW de Diamantina.

A zona de cisalhamento de teto do duplex pode ser observada na borda oeste da cordilheira, em Rodeador. Nesta área foi observado dobra anticlinal, com eixo inclinado e com os flancos rompidos por falhas de empurrão. No núcleo do anticlinal estão expostas as sucessões da fase flexural da Bacia Espinhaço. São recobertas de forma discordante pelos metadiamictitos da fase rift 2 da Bacia São Francisco. Para sul, este anticlinal torna-se revirado, com a inversão do acamamento sedimentar devido ao arrasto ao longo da zona de cisalhamento de teto.

Foram identificados dois estilos diferentes de deformação, respectivamente abaixo e acima da zona de cisalhamento de teto do duplex. Abaixo da zona de cisalhamento de teto, a deformação é representada por cavalgamentos subsidiários, marcados por padrão tectônico sigmoidal, penetrativo em todas as escalas (Fig. 5). Os cavalgamentos subsidiários delimitam fisicamente os cavalos tectônicos. A deformação de rochas é muito intensa e a transposição de estruturas sedimentares é uma regra geral. No interior dos cavalos tectônicos, foi observado dobras de rumo N/S, sinformal-antiformal. Estas dobras deformam a foliação tectônica principal e o acamamento sedimentar. As dobras são assimétricas, vergentes para oeste, com os flancos menores rompidos em decorrência do arrasto ao longo dos cavalgamentos subsidiários (Fig. 6). A foliação tectônica principal se orienta paralelo ao acamamento sedimentar e ocorre na forma de clivagem ardosiana, clivagem espaçada ou mesmo na forma de xistosidade, dependendo do litotipo na qual é desenvolvida. Nas rochas metapelíticas são observadas zonas de cisalhamento, de espessuras milimétricas, orientadas paralelas com o acamamento primário. Rochas cataclásticas ocorrem nos planos de falhas inversas. Dobras em bainha pequenas são geradas nas zonas de cisalhamento.

$\mathrm{Na}$ área de Gouveia pode ser observada uma sucessão de três anticlinais, com eixos inclinados suavemente para norte e com planos axiais íngremes para leste. O complexo do embasamento aflora no núcleo dos anticlinais, que possuem flancos rompidos por falhas inversas. O Embasamento Arqueano é recoberto por meta-argilitos (filitos) da base da fase pré-rift 1 . Perto do contato com as rochas metassedimentares, o granito adquire foliação tectônica espaçada, concordante com o acamamento sedimentar e a foliação tectônica predominante das rochas metassedimentares sobrejacentes.

$\mathrm{Na}$ área de Guinda, foram mapeadas duas zonas de cisalhamento transcorrentes, orientadas aproximadamente $\mathrm{E} / \mathrm{O}$, com movimentação tectônica no sentido anti-horário. Na região das proximidades das zonas de cisalhamentos transcorrentes, a foliação tectônica e o acamamento sedimentar são dobrados progressivamente até tornarem-se orientados paralelos com o plano das falhas. Uma explicação plausível é de que as zonas de cisalhamento transcorrentes se desenvolveram como solução para a disputa de espaços físicos entre as áreas para sul e para norte das falhas, que possuem diferentes deslocamentos tectônicos frontais. Outra possibilidade para a origem das zonas transcorrentes é que estas representam as rampas laterais dos cavalgamentos frontais.

Acima da zona de cisalhamento de teto do duplex, a deformação é caracterizada por um sistema de lentes tectônicas imbricadas, cujas falhas inversas convergem para baixo em direção à zona de cisalhamento de teto do duplex. No interior das lentes tectônicas, a deformação de rochas não é intensa e é comum a preservação de estruturas sedimentares. A distância entre as lentes tectônicas é muito maior quando comparado com a distância entre os cavalos tectônicos.

Dentro das lentes tectônicas, foram observadas dobras com rumo N/S, sinformal/antiformal, que deformam tanto a foliação tectônica quanto o acamamento sedimentar. A amplitute destas dobras é muito maior quando comparado com a amplitude das dobras sinformais/antiformais observadas no interior dos cavalos tectônicos do duplex. Isto explica porque na área de Conselheiro Mata afloram quatro lentes tectônicas subsequentes, todas apresentando dobras sinformais, com flanco menor rompido nos planos de falhas de empurrão. O nível de erosão atual impede a exposição das partes superiores destas lentes tectônicas, restando assim somente as porções inferiores.

EVOLUÇÃO TECTÔNICA A deformação das lentes tectônicas e dos cavalos tectônicos, após o imbricamento tectônico, registra a superposição de estruturas da fase deformacional D2 nas estruturas tectônicas relacionadas à fase deformacional D1. 


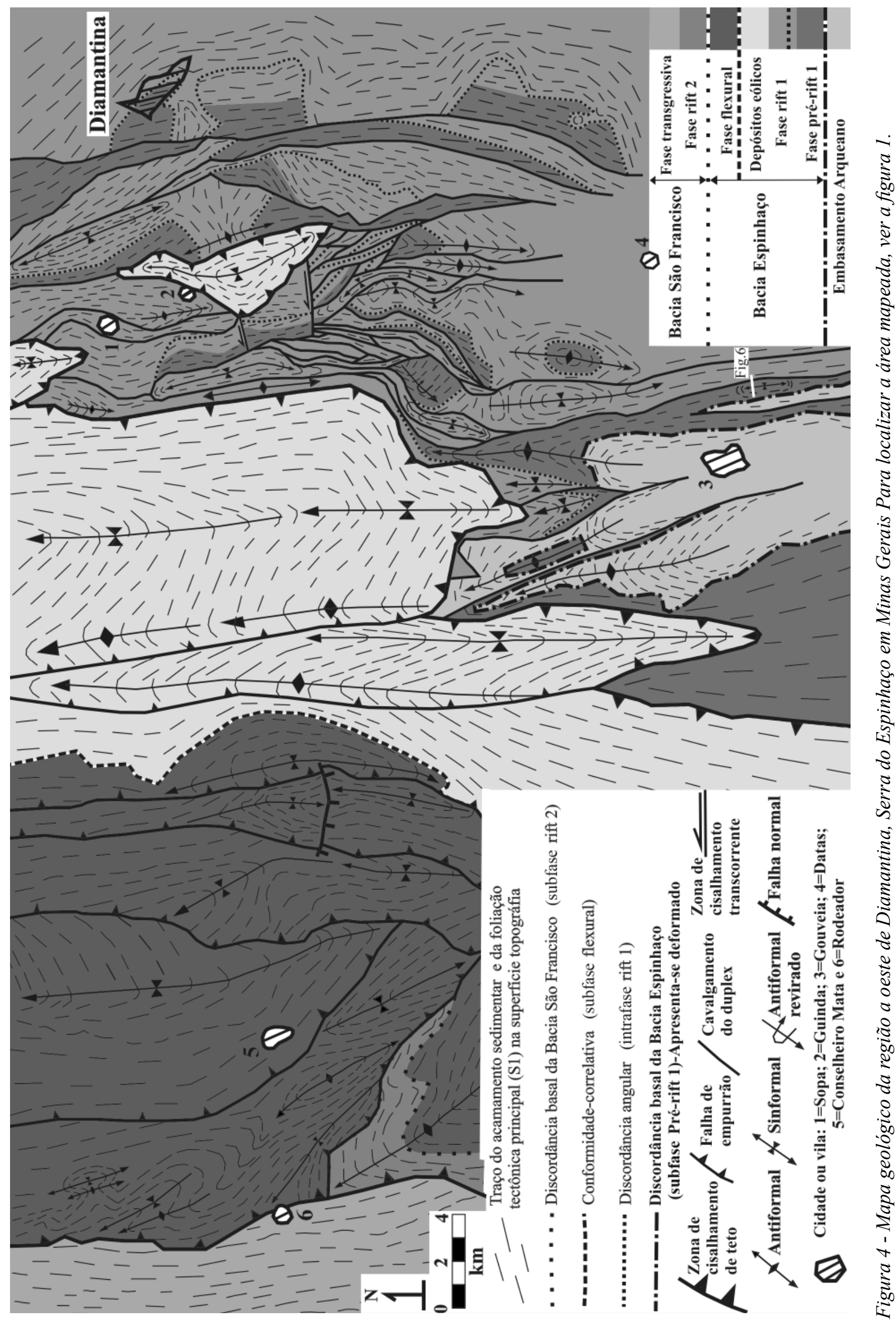




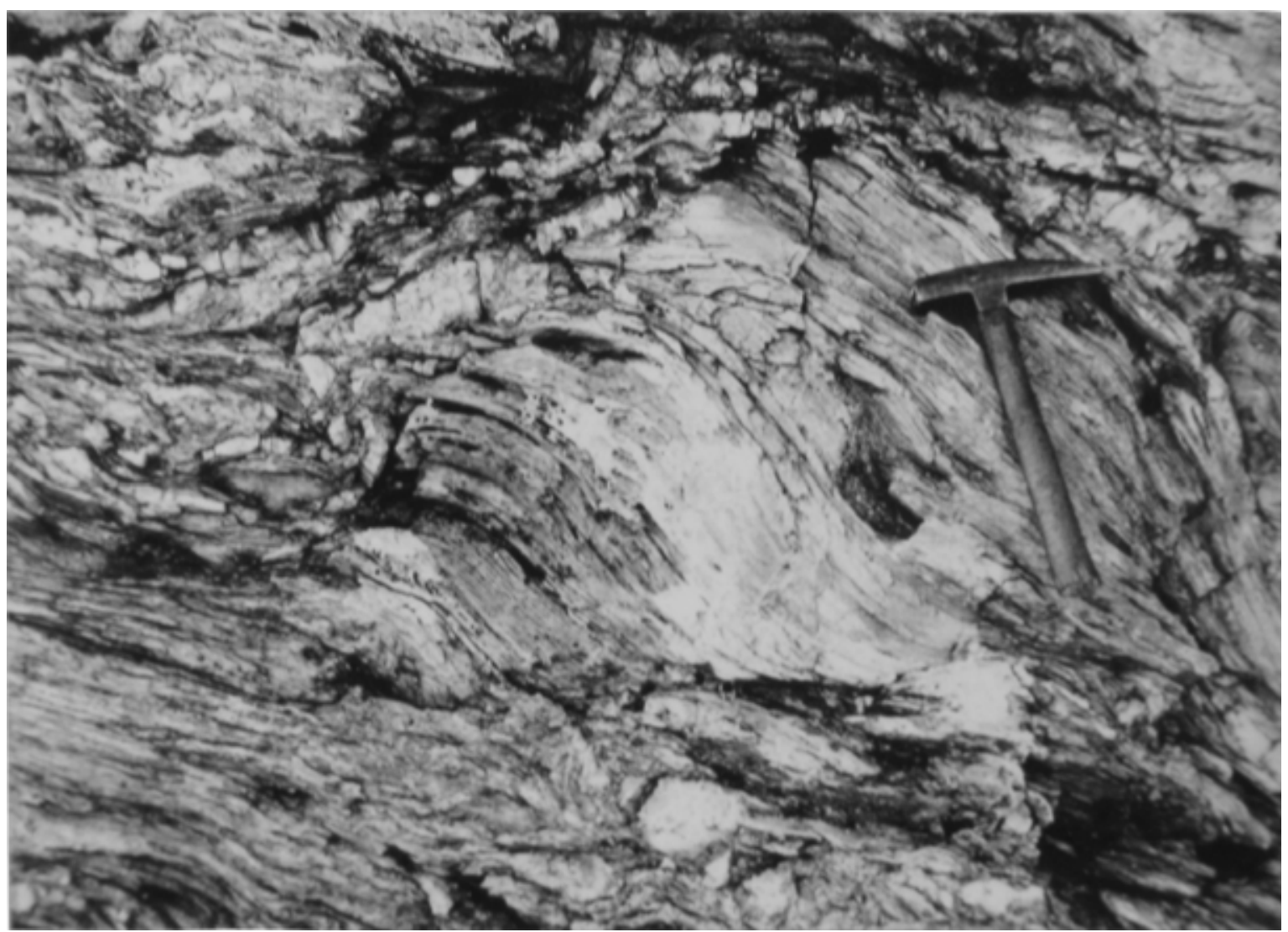

Figura 5 - Padrão tectônico sigmoidal impresso de forma penetrativa em sericita-quartzo-xistos da Sequência Deposicional Rio Paraúna, Fase Pré-Rift 1 da bacia do Espinhaço (Silva \& Toledo 1994, Silva 1995).

O sistema de cavalgamentos do tipo duplex da Serra do Espinhaço em Minas Gerais foi construído durante a primeira fase de deformação D1. Uma foliação tectônica principal (S1) é desenvolvida paralela com o acamamento sedimentar. O transporte tectônico durante D1 é direcionado para oeste, como indicado por estrias de falhas e lineações de estiramento desenvolvidas nos planos de cavalgamentos da fase deformacional D1 e por uma lineação mineral penetrativa, observada nos planos de foliação tectônica S1.

A deformação D2 é representada por dobramento sinformal-antiformal, na maioria dos casos com flancos rompidos. Localmente, nas zonas de charneira das dobras D2, é desenvolvida uma foliação plano-axial S2, com transposição da foliação tectônica S1 e do acamamento sedimentar. Os planos de cavalgamentos da fase deformacional D1 não foram dobrados durante a segunda fase de deformação D2. Nossa interpretação é que os planos de cavalgamentos e as zonas de cisalhamento D1 foram reativados durante D2 para absorver o encurtamento crustal. É bem provável que o par antiformal-sinformal, observado no interior das lentes tectônicas e dos cavalos tectônicos, tenha sido nucleado durante D1 e desenvolvido durante D2.

As relações espaciais entre as estruturas desenvolvidas durante as fases D1 e D2 são marcantes. A figura 7 apresenta os estereogramas das estruturas tectônicas desenvolvidas durante as fases deformacionais D1 e D2, na área entre Diamantina e Gouveia. A foliação tectônica principal S1 orienta-se paralelo com o acamamento sedimentar, com frequência máxima de $95^{\circ} / 32^{\circ}$. A lineação mineral L1 está posicionada ao longo do mergulho da foliação $\mathrm{S} 1$, com frequência máxima $74^{\circ} / 24^{\circ}$, indicando transporte tectônico frontal direcionado para oeste. Durante D2 o encurtamento crustal foi obtido principalmente a partir do dobramento assimétrico, penetrativo, deformando a foliação $\mathrm{S} 1$ e o acamamento sedimentar. As foliações tectônicas S2 orientam-se em média para $85^{\circ} / 72^{\circ}$ e as lineações tectônicas L2 estão preferencialmente posicionadas N-S, horizontais $\left(353^{\circ} / 00^{\circ}\right)$.

METAMORFISMO As associações de minerais metamórficos são tipicamente compostas por fengita, muscovita, quartzo, cianita, pirofilita, turmalina, clorita, cloritoide, lazulita, estilpnomelana, magnetita e minerais opacos. Estas associações de minerais metamórficos são características de condições inferiores de fácies xisto verde (Winkler 1977, p. 209).

Com base na interpretação das relações de porfiroblastos de cianita e muscovita com a foliação tectônica S1, o pico metamórfico sintectônico pode ser localizado durante a segunda fase de deformação (D2). 

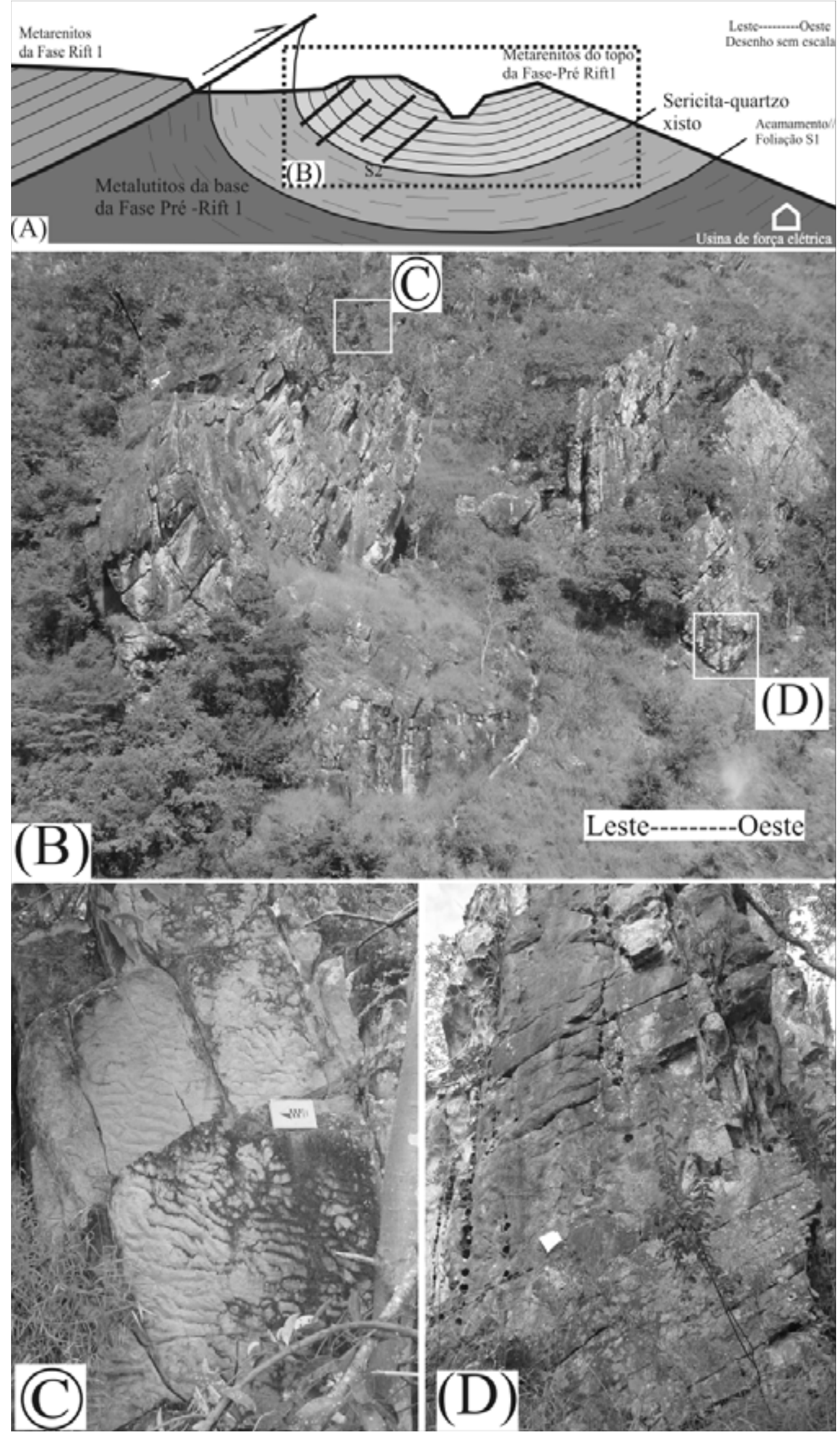

Figura 6 - (A) Perfil geológico esquemático na represa de São Roberto, a leste de Gouveia. Para localizar o perfil ver mapa geológico da figura 4. (B) Fotografia do sinclinal que ocorre em decorrência do arrasto ao longo do cavalgamento. Observar o dobramento do acamamento sedimentar e o desenvolvimento de foliação tectônica S2 (plano-axial). (C) Metarenitos posicionados no flanco rompido do sinclinal possuem acamamento sedimentar (marcas de onda) orientado sub-meridional, com inclinação ingreme a vertical. (D) Metarenitos no flanco normal do sinclinal, possuem mergulhos orientados para leste. 
(A) Orientação dos polos da
foliação tectônica $S 1$

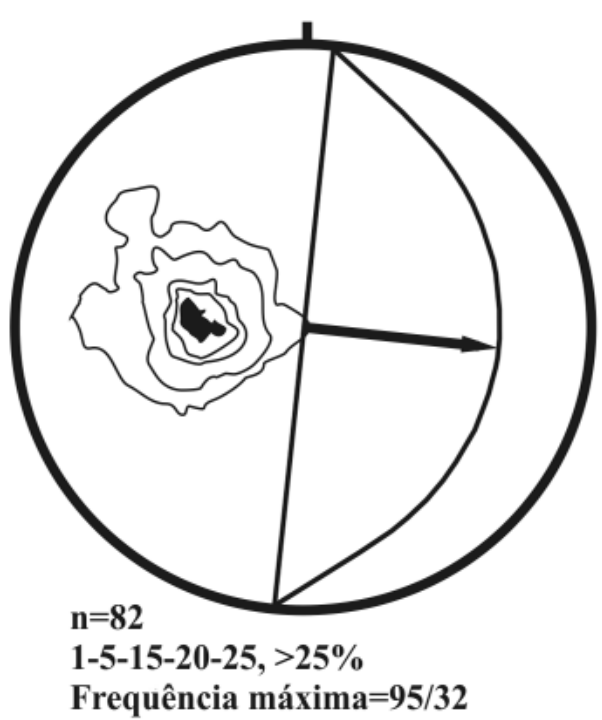

(B) Orientação da lineação tectônica L1

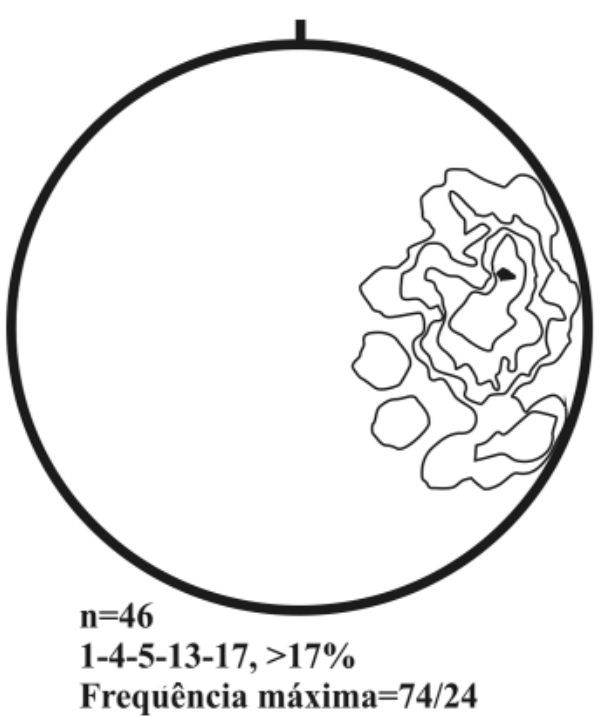

(C) Orientação dos polos da foliação tectônica S2

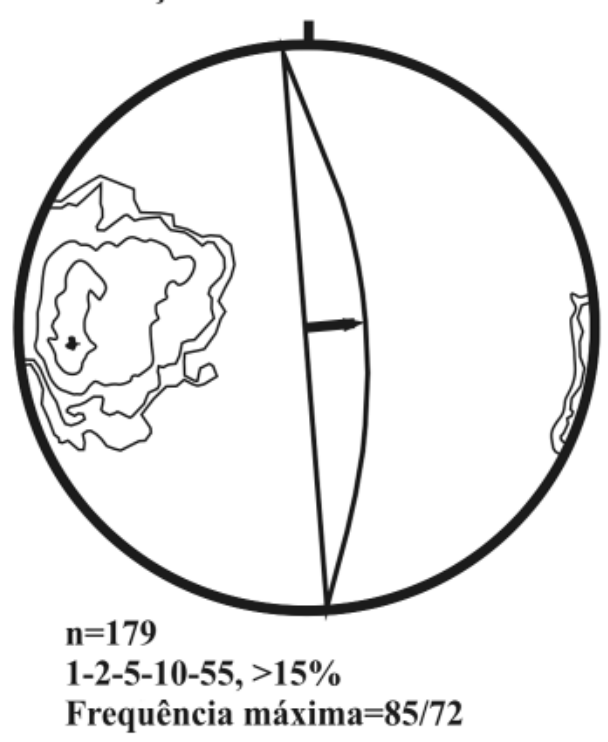

(D) Orientação da lineação tectônica $\mathrm{L2}$

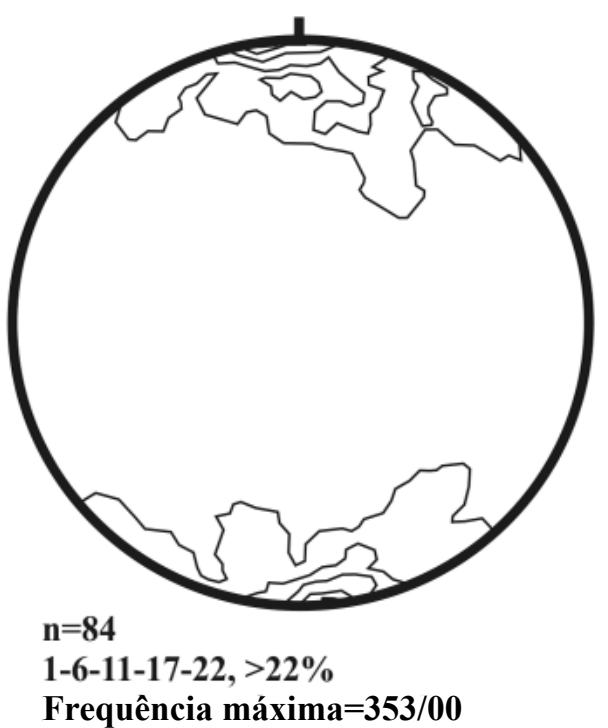

Figura 7 - Estereogramas das estruturas geradas durante as fases deformacionais D1 e D2, na área entre Diamantina e Gouveia (Silva 1995). S1 é xistosidade nos sericita-quartzo- xistos da fase pré-rift. L1 representa a lineação mineral e a lineação de estiramento; $S 2$ representa a clivagem de crenulação, clivagem espaçada e planos axiais de dobras e L2 representa lineação de crenulação, eixos de dobras e lineações de interseção.

Nos metapelitos e nos cianita-sericita-quartzo xistos, foram observadas crenulações da clivagem ardosiana S1. Fengita e cianita milimétricas, cristalizadas no plano de foliação tectônica S1, foram deformadas e recristalizadas como porfiroblastos centimétricos nos planos de clivagem de crenulação (S2). Uma mudança progressiva nas condições metamórficas durante e evolução tectônica (desde D1 até D2) pode ser demonstrada pela transformação de fengita para muscovita e pelo crescimento, deformação e recristalização de cianita nos planos de foliação tectônica S2.

A mudança da deformação predominantemente rúptil, ocorrida durante $\mathrm{D} 1$, representada pelo desenvolvimento de cavalgamentos, para deformação predominantemente dúctil, ocorrida durante D2, exemplificada pelo dobramento generalizado, também confirma 
a hipótese do aumento progressivo das condições metamórficas sintectônicas. Os cavalgamentos ocorridos durante D1 provavelmente causaram espessamento crustal e consequentemente o aumento das condições metamórficas durante D2.

CONCLUSÕES A utilização de métodos apropriados de análise estratigráfica permitiu a reconstrução das bacias sedimentares e, consequentemente permitiu também a realização de análise estrutural para a região. $\mathrm{O}$ arcabouço tectônico da Serra do Espinhaço em Minas Gerais é caracterizado pelo desenvolvimento de um sistema de cavalgamentos do tipo duplex de
A figura 8 é um perfil geológico conjugado da área mapeada. Este perfil é interpretativo e foi elaborado a partir das relações observadas no campo e apresentadas no mapa geológico. Para facilitar a comparação entre o perfil conjugado com o mapa geológico, foi acrescentada a localização relativa de algumas cidades ou distritos. O modelo de duplex apresentado na Serra do Espinhaço em Minas Gerais difere do modelo apresentado por Boyer \& Elliot (1982). Estes autores descrevem o sistema duplex, com o deslocamento tectônico de uma nappe isolada. O que foi observado aqui é o desenvolvimento de um sistema de lentes tectônicas, cujas falhas inversas conectam-se abaixo, na zona de cisalhamento de teto do duplex.

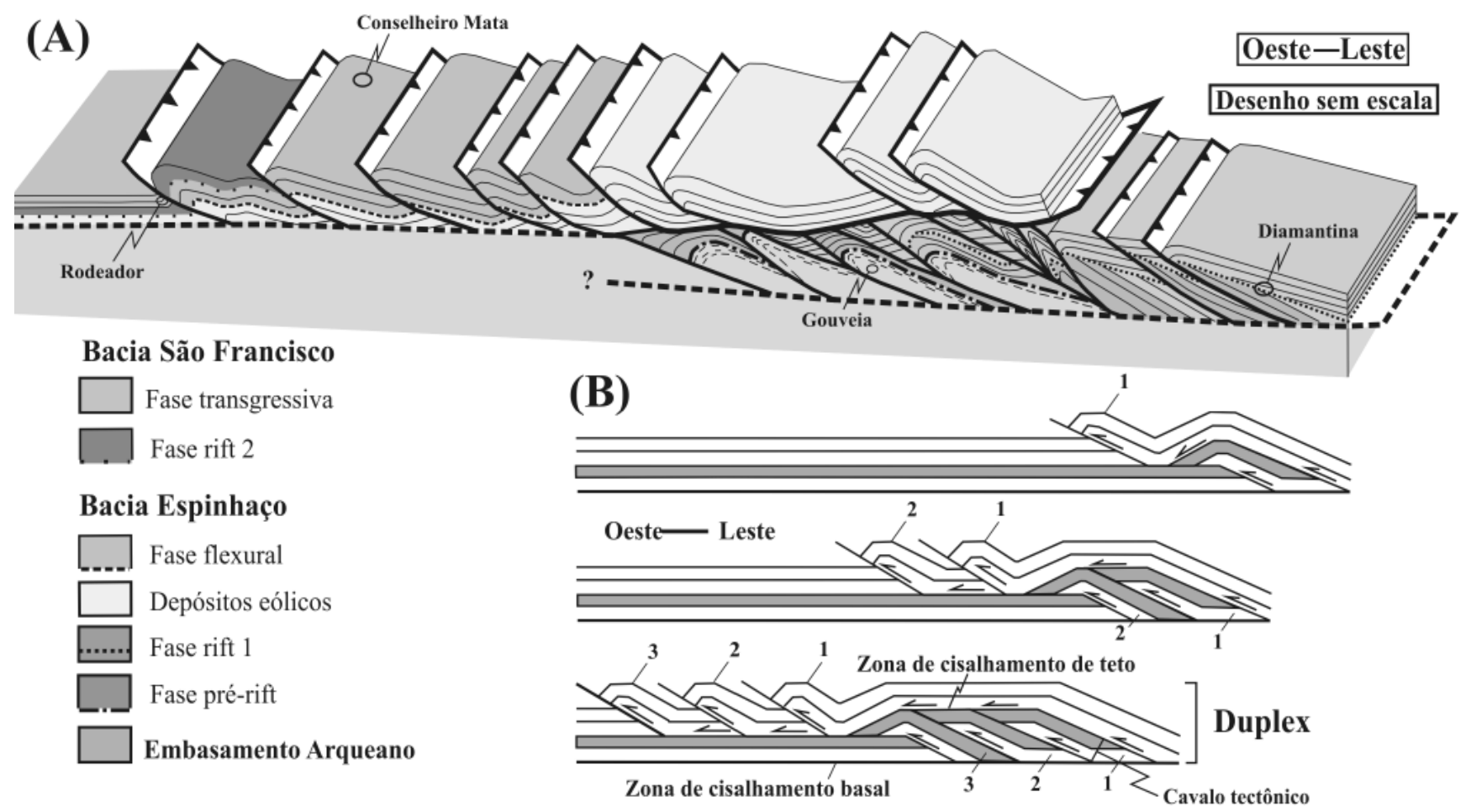

Figura 8. (A) Perfil estrutural conjugado da porção central da Serra do Espinhaço meridional em Minas Gerais (após Silva \& Toledo 1994, modificado). (B) Modelo do desenvolvimento do sistema de cavalgamentos do tipo duplex da Serra do Espinhaço meridional em Minas Gerais (após Boyer \& Elliot 1982, modificado). A distância horizontal na direção leste/oeste apresentada no perfil representa aproximadamente $50 \mathrm{~km}$.

importância regional. O transporte tectônico foi direcionado para oeste. Foi heterogênea, de caráter rúptil/ dúctil e por cisalhamento simples. Durante a fase inicial de deformação D1, foi desenvolvido o sistema de cavalgamentos do tipo duplex. A fase de deformação D2 foi responsável pelo encurtamento crustal, obtido através de dobramento assimétrico generalizado e pela reativação dos cavalgamentos D2. Durante a deformação ocorreu metamorfismo progressivo, quando foram cristalizadas associações de minerais metamórficos com características de condições inferiores de fácies xisto verde.
Agradecimentos Este artigo é resultado direto da minha atividade de docência de mapeamento geológico, desde 1987, no Centro de Geologia Eschwege em Diamantina, Minas Gerais, atual Casa da Glória/ IGC/UFMG. Devo agradecer primeiramente aos alunos de diversas universidades desde país, que me acompanharam e tornaram possível a realização deste trabalho. Devo agradecimentos também aos funcionários da Casa da Glória e aos colegas de ofício. Agradecimentos aos professores Ricardo Diniz da Costa e Luís Guilherme Knauer, ambos do CPMTC/ IGC/UFMG, que gentilmente leram a primeira versão 
deste artigo e contribuíram para melhorá-lo. Agradeço ainda a dois revisores anônimos da Revista Brasileira de
Geociências, que em muito contribuíram para melhorar a versão final deste manuscrito.

\section{Referências}

Boyer S.E. \& Elliot D. 1982. Thrust systems. Am. Ass. Petrol. Geol., 66:1196-1230.

Brito-Neves B.B., Kawashita K., Cordani U.G., Delhal J. 1979. A evolução geocronológica da Cordilheira do Espinhaço, dados novos e integração. Rev.Bras. Geoc., 9:71-85.

Cruz S.C.P., Alkmim F.F., Lagoeiro L.E. 2005. Zona de cisalhamento do núcleo do anticlinório de Gouveia, cordilheira do Espinhaço, MG: geometria, cinemática e processos deformacionais. Rev. Bras. Geoc., 35(4):441452.

Danderfer A. \& Dardenne M.A. 2002. Tectonoestratigrafia da Bacia Espinhaço na porção centro-norte do Craton do São Francisco: registro de uma evolução poliistórica descontínua. Rev. Bras. Geoc. 32(4):449-460.

Danderfer A., De Waele B., Pedreira A.J., Nalini A.H. 2009. New geochronological constraints on the geological evolution of the Espinhaço basin within the São Francisco Craton - Brazil. Precambrian Research, 170:116-128.

Dominguez J.M.L. 1993. As coberturas do Craton do São Francisco: uma abordagem do ponto de vista da análise de bacias. In: Dominguez M. \& Misi A. (eds.). O Craton do São Francisco. Salvador, SBG/SGM/CNPq, p. 137159.

Dossin I.A., Dossin T.M., Charvet J., Chemale Jr. 1992. Tectonique du Protérozoique au sud-est Craton São Francisco (Minas Gerais, Brésil). C.R. Acad. Sci. Paris, 315(II):629-636.

Kalt H. 1991. Untersuchungen zur Schertektonik in der südlichen Serra do Espinhaço und im angrenzenden Teil des São Francisco-Beckens, Minas Gerais, Brasilien. Tese de Doutorado, Universidade de Freiburg, Alemanha, $247 \mathrm{p}$.

Machado N., Schrank A., Abreu F.R., Knauer L.G., Almeida-Abreu P.A. 1989. Resultados preliminares da geocronologia $\mathrm{U} / \mathrm{Pb}$ na Serra do Espinhaço meridional. In: SBG, Simp. Geol. Minas Gerais, 5, Atas, p. 171-174.

Marshak S. \& Alkmim F.F. 1989. Proterozoic contraction/ extension tectonics of the southern São Francisco region, Minas Gerais, Brazil. Tectonics, 8:555-571.

Martins M., Karfunkel J., Noce C.M., Babinsk M., PedrosaSoares A.C., Sial A.N., Liu D. 2008. A seqüência préglacial do Grupo Macaúbas na área-tipo e o registro de abertura do rift Araçuaí. Rev. Bras. Geoc., 38(4):761772.

Martins-Neto M.A. 1998. O Supergrupo Espinhaço em Minas Gerais: registro de uma bacia rifte-sag do Paleo/ Mesoproterozóico. Rev. Bras.Geoc., 28(2):151-168.

Martins-Neto M.A. 1995. A evolução tectônica da Bacia Espinhaço no Estado de Minas Gerais. In: SNET - Simp. Nac. Est. Tect., 5, Anais, p. 287-289.

Pedrosa-Soares A.C., Noce C.M., Vidal P., Monteiro R.L.B.P., Leonardos O.H. 1992. Toward a new tectonic model for the Late-Proterozoic Araçuaí (SE Brazil)-West Congolian (SW África) Belt. Journal of South American Earth Sciences, 6(1/2):33-47.

Pflug R. \& Renger F. 1973. Estratigrafia e evolução geológica da margem SE do Cráton Sanfranciscano. In: SBG, Cong. Bras. Geol., 27, Anais, p. 5-19.

Pflug R. 1968. Observações sobre a estratigrafia da Série Minas na região de Diamantina, Minas Gerais. Rio de Janeiro, DNPM/ Divisão Geologia e Mineração, Boletim $142,20 \mathrm{p}$.

Posamentier H.W., Jervey M.T., Vail P.R. 1988. Eustatic controls on clastic deposition I - conceptual framework. SEPM Spec. Publ., 42:109-124.

Ribeiro A. 1997. Estratigrafia e peleoambientes nas sucessões metassedimentares Proterozóica das Serras do lenheiro e São José, São João Del Rei, sul de Minas Gerais. Tese de Doutorado, Instituto de Geociências, Universidade Federal do Rio de Janeiro, Rio de Janeiro, $167 \mathrm{p}$.

Ribeiro A., Trouw R.A.J., Paciullo F.V.P., Valença J.G. 1997. Evolução das bacias Proterozóicas e o termo-tectonismo Brasiliano na margem sul do Cráton do São Francisco. Rev. Bras. Geoc., 4:235-248.

Rolim V.K. 1992. Uma interpretação das estruturas tectônicas do Supergrupo Espinhaço, baseado na geometria dos falhamentos de empurrão. Rev. Esc. Minas, 45:75-77.

Schobbenhaus C. 1993. O Proterozóico Médio no Brasil com ênfase à região Centro-Leste: uma revisão. Tese de Doutorado, Universidade de Freiburg, Alemanha, 166p.

Schöll W.Ü. 1980. Estratigrafia, sedimentologia e paleogeografia na região de Diamantina (Serra do Espinhaço, Minas Gerais, Brasil). Münster Forsch. Geol. Paläont., 51:223-240.

Schöll W.Ü. \& Fogaça A.C.C. 1981. Mapa geológico da Quadrícula de Guinda. Diamantina, DNPM/Centro de Geologia Eschwege, mapa geológico, escala 1:25.000.

Silva R.R. 2008. The structural framework of the southern Serra do Espinhaço in Minas Gerais, Brazil: an example of duplex thrust system. In: APG, Cong. Latino Americano de Geologia, 15, Lima, Peru, Resumos Expandidos, CD-ROM, G-14, 6 p.

Silva R.R. 1999. As Bacias Proterozóicas do Espinhaço e São Francisco: uma abordagem sob o ponto de vista da estratigrafia de seqüências. Geonomos, 6(2):1-13.

Silva R.R. 1996. Correlation of the deposicional sequences of the Proterozoic Espinhaço and São Francisco Basins, in Minas Gerais and Bahia States. In: SBG, Cong. Bras. Geol., 39, Atas, 6:142-144.

Silva R.R. 1995. Contribution to the stratigraphy and paleogeography of the lower Espinhaço Supergroup (Mesoproterozoic) between Diamantina and Gouveia, Minas Gerais State, Brazil. Freiburger Geowissenchaftliche Beiträge, 8:1-115. 
Silva R.R. 1994. Depositional sequences of the rift phase of the Proterozoic Espinhaço Supergrupo, in the área between Diamantina and Gouveia, Minas Gerais, Brazil. In: IGS, Intern. Sedimen. Congr., 14, Rio de Janeiro RJ, Abstracts, G:75-76.

Silva R.R. 1993. Seqüências estratigráficas da fase rift do Supergrupo Espinhaço, Diamantina, Minas Gerais. In: SBG, Simp. do Cráton do São Francisco, 2, Anais, p. 154-157.
Silva R.R. \& Toledo C.L.B. 1994. A Proterozoic duplex thrust system in the southern Serra do Espinhaço, Minas Gerais, Brazil. Zbl. Geol. Paläont., 1(1/2):55-66.

Winkler H.G.F. 1977. Petrogenesis of Metamorphic Rocks. 5a Ed. New York, Springer-Verlag, 348 p.

Manuscrito ID 14478

Submetido em 15 de setembro de 2009

Aceito em 17 de dezembro de 2010 